\title{
Walking Through A Maze: The Struggles of Accountancy Students with Online Learning in the Context of the COVID-19 Pandemic
}

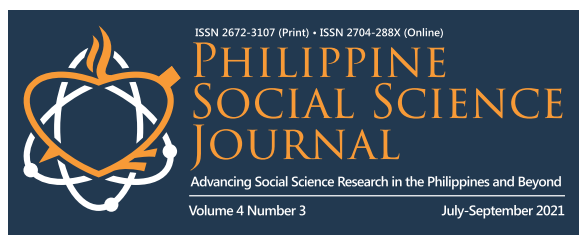

Grace L. Lopena ${ }^{1}$, Nenette D. Padilla ${ }^{2}$, and Dennis V. Madrigal ${ }^{3}$

1, 2,3 University of Negros Occidental-Recoletos, Bacolod City, Philippines

\section{Article history:}

Submitted: 15 June 2021

Revised: 15 October 2021

Accepted: 25 October 2021

\section{Keywords:}

Online learning

Phenomenology

Accountancy students

COVID-19 pandemic

Bacolod City
Business education

ABSTRACT. This descriptive phenomenological paper reflects the students' lived experiences metaphorically likened to 'walking through a maze,' their struggles with online learning in the context of COVID-19 construed as obstacles. Such experiences play a role in their academic successes or failures, shaped by various factors like learning environment, peers, instructors, living situations, and curriculum. Given the COVID-19 pandemic and urgency for remote learning, it becomes imperative to understand the effects of this abrupt change. Thus, this paper seeks to narrate the lived experiences of accountancy students from a higher education institution (HEI) in Bacolod City. Four participants were selected for in-depth interviews through a gatekeeper who was the Accountancy program head. Through a thematic analysis, findings revealed the students' difficulties. These struggles, however, were integral to cultivating resilience and capacity for adaptation. While the concluding outlook is perceived as positive, the need to mitigate the effects of students' negative lived experiences remains crucial.

\subsection{Introduction}

With the outbreak of COVID-19, most, if not all, countries worldwide have been forced to indefinitely phase out traditional classroom-based education in favor of online learning. It is an adjustment that comes in compliance with the movement restriction measures that their respective governments have taken, necessary to curb the spread of the pandemic. The COVID-19 has resulted in schools shut across the world. Globally, over 1.2 billion children are out of the classroom because of the pandemic (World Economic Forum, 2020).

For instance, in Southeast Asia, educational institutions have implemented virtual and distance learning as alternatives to traditional classroom-based education (Eddin, 2020). However, this abrupt implementation has raised concerns about whether the ASEAN education systems are sufficiently prepared for online education being conducted at such large scales. The pandemic exposed steep disparities encompassing gender, income, and other socio-economic factors. Many stakeholders lack access to the internet, computers, or vital technical skills needed to participate in online learning. Students are challenged because of no internet access, and these inequalities deeply affect the learner population in these countries. Of many countries, 80 percent of the populations of Singapore, Brunei, and Malaysia have internet access; in contrast, less than 60 percent of the populations of Indonesia, Thailand, and Cambodia possess internet connectivity. In comparison, only around 40 percent of the populations of Myanmar and Vietnam have been penetrated by internet usage (Yarrow, 2020).

The Philippines is no exception to this sudden change. Schools nationwide had been obliged to end the previous school year early last March, with subsequent delays in beginning the next one. Last year, President Rodrigo Duterte declared via a televised address that students would not be allowed to return to schools until a vaccine for COVID-19 has been made available and that doing otherwise would "spell disaster." Such a decision, despite being well intended, has been met with resistance. The Samahan ng Progresibong Kabataan (SPARK) has repeatedly appealed to both the Department of Education (DepEd) and Commission on Higher Education (CHED) to enact an 'academic freeze,' one which would temporarily suspend classes until at least January. The group's first plea came about from only 15.9 million in the elementary and secondary levels were enrolled. According to a DepEd report, enrollment is 12 million short of the projected figure by DepEd Secretary Leonor Briones. but not in any way that suggests the licensor endorses you or your use. You may not use the material for commercial purposes. 
SPARK had stated that if 12 million students were already excluded, then students' plight would only worsen with time (Hallare, 2020).

Although SPARK's pleas have been opposed at different turns, particularly by the Coordinating Council of Private Educational Associations [COCOPEA] (San Juan, 2020), with schools continuing to start the new school year - albeit at different dates, such appeals are substantiated by the alarming number of students taking to social media and other platforms as a means of airing out their woes about the pitfalls of remote learning.

In Bacolod City and other parts of Negros Occidental, to comply with government and statesupported regulations as per CHED Memorandum No. 04 Series of 2020, some universities, specifically privately-run, started their online classes in August 2020. Some adopted a schedule like face-to-face, while the university where the researcher is affiliated started the new school year for the tertiary level in three phases, each phase having its midterm and final periods. Education was primarily conducted through online and offline sessions.

Literature shows that there have been studies on online classes. However, these delved into and explored the experiences of other programs before the pandemic. Studies were conducted on the lived experiences of online and experiential learning programs in four undergraduate professional programs like nursing, education, and business (Snow et al., 2019). Another study is the students' positive and negative experiences in a hybrid and online class by Mansour and Mupinga (2007). There was also a study before the COVID 19 pandemic on the new approaches to online accounting education (Myring et al., 2014). However, studies on the experiences of accountancy students with online classes during the COVID-19 pandemic are scant. Thus, this study hopes to address the literature gap on the subject, more specifically on the narration or description of the accountancy students' experiences with online classes specifically held within the context of the COVID 19 pandemic.

Given that the Philippines is a country where formal education dominates within the traditional classroom-based setup, a nationwide mandate to shift to remote learning would foster new realities, with virtually few studies conducted in contextualizing the circumstances. Therefore, conducting research of this nature is vital to making sense of the influx of new experiences brought about by the COVID-19 pandemic and addressing the succeeding literature gap. Henceforth, this study sought to explore the experiences of the university's undergraduate accountancy students with online classes amid the COVID-19 pandemic as everyone struggles to adapt to what is widely called the 'new normal.'

\subsection{Methods}

This is qualitative research that viewed and analyzed the purpose statement using the descriptive phenomenological approach. The approach helped explore, describe, and understand the essence of the participants' experiences with online classes. Qualitative research was used to explore and understand the meanings that individuals or groups ascribe to a social or human problem (Creswell, 2014). For the meanings attached to the experiences of accountancy students to be emphasized, the study acknowledged theories, philosophies, principles, and philosophical assumptions to strengthen its structures. The researcher acknowledged that the study has philosophical assumptions from ontological, axiological, epistemological, and methodological viewpoints.

In the selection of qualified conversation partners, the researcher used purposive sampling. The gatekeeper of this study was the head of the accountancy program as the key informant. The perceived role of the gatekeeper in qualitative research is to provide access to archival sites and determine why the site was selected for the study. In this study, she provided access to the site and allowed or permitted the research to be done (Creswell, 2014). To be qualified and included in the study, the following were the inclusion criteria: the participants should be an accountancy student from each year level and must be a scholar, single, officially enrolled in the first semester for the academic year 2020-2021, and with adequate information technology resources. Adequacy of information technology resources means the participants have gadgets used during online classes and good internet connectivity to handle various learning management system platforms.

The in-depth interview was used to understand the participants' experiences and the meaning they made, reconstructed, and reflected from these experiences (Creswell, 2014). The success of the data gathering method depended on the researcher. The researcher prepared an interview guide before the actual interview. Rapport was first established with the participants before the interview. 
The researcher apprised the participants of their rights before interviewing them. As the study used narratives and descriptions, the interview started with a semi-structured question. From this, the researcher probed into the participant's experiences under study. From the participant's narratives, follow-up questions were asked until the description of the phenomenon was culled out. After the interview, the researcher debriefed the participants by ensuring that the participants were relieved and happy.

Preliminary data gathering started with the researcher's establishment of contacts with the gatekeeper, who is the accountancy program head, to identify the target participants of the study. The researcher had previously coordinated with the gatekeeper to ascertain that the participants met the criteria enumerated in the scope of the study.

Given that the initial data were obtained from interviews, data analysis commenced. Data analysis was guided by the concepts of the three Cs (Lichtman, 2012). As the series of the interview was recorded, the data were transcribed verbatim using the number line. Initially, the researcher read the transcripts per number line to obtain the details; re-reading followed. The researcher used the code-recode strategy on dependability.

\subsection{Results and Discussion}

\section{Participants}

Jose. The first male participant was Jose, 21 years old and a third-year accountancy student. He resides in Bago City and has been a consistent academic scholar. He has two siblings, a brother, and a sister, and he is the youngest. His ultimate goal as an accountancy student is to pass the Certified Public Accountant (CPA) board exam, and it would be a bonus if ever he becomes one of the topnotchers.

Juan. The second male participant was Juan, 20 years old and a second-year accountancy student. He resides in Talisay and has been a consistent academic scholar. He has two siblings, a brother, and a sister, and he is the youngest. His goal is to graduate from the accountancy program and become a CPA. He wants to engage in public practice someday.

Maria. The third participant was Maria, a female, 19 years old, and a first-year accountancy student. She resides in Bacolod City and is a scholar. She has three siblings, one brother, and two sisters. Her goals are to maintain her scholarship, graduate with Latin honors, and hopefully use and apply her learnings as an accountancy student in her future career.

Elena. The fourth participant was Elena, a female, 19 years old, and a first-year accountancy student. She resides in Bacolod City and is a scholar. She has one brother. Her goals are to graduate in college with flying colors while being committed to God, pass the board examination and belong to the top passers, become a financially literate person, and save money for the equity of the house. She wants to become a CPA lawyer someday.

\section{Metaphor: walking through a maze}

A maze has three parts: entrance, challenge, and exit. Though the goal is simple, that is, to get to the exit, the challenge lies in navigating through a circuitous route that leads to numerous dead-ends and several routes to the exit. The series of mazes might be familiar but have different paths (due to different courses enrolled in a term) and must be sustained (from entry to exit) within a definite environment (internet, time, class phase). This can be likened to an online teaching/learning modality that is hastily prepared and implemented. This unpreparedness will lead to dead ends, which is a failure to transmit and absorb knowledge. This unpreparedness, too, will result in hits and misses. Surely something good will also come out, albeit unprepared; however, the result will not be as effective, hence the maze' metaphor on circuitous routes that will eventually lead to the exit as students persevere in online classes.

Navigating through a maze repeatedly, one eventually finds the shortest route from the entrance to the exit. The assistance of future researchers will be needed to streamline the online teaching/ learning modality and reduce the negative experiences of the respondents. Leaving students on their own to find the most effective way of adapting and adjusting with an online learning modality will take time and cause missed opportunities in the knowledge and skills transmittal and absorption. 


\title{
Struggling with online learning
}

Learning online, a necessity because of the pandemic, is a challenge. Students need to contend with issues brought about by this teaching modality. Both students and teachers are struggling with burnout as they try to adjust to the new normal of online school (Chen, 2020). Online learning is not an unfamiliar concept and has already been implemented by institutions worldwide, though not on a scale comparable to learning within a physical classroom setting. Given the rate at which technological advancement is rapidly made and its further integration into society, it becomes necessary to improve online learning as a mode of delivery as it deals with the struggles it entails.

There has been a disruption in online learning, but not how technology companies and educational futurists had anticipated. One may logically contend that the frantic scramble of emergency online instruction over the last months cannot be equaled to well-planned and welldesigned online learning (Burns, 2020).

Though the industry and the academe have used this teaching modality to supplement traditional face-to-face teaching modality, issues are magnified like never before when used continuously. In the pre-pandemic era, online teaching was used by institutions when the actual onsite ocular inspection was not feasible or allowed. Likewise, during the pre-pandemic era, the academe used online teaching for packaged, modular sessions reinforced with the traditional face-to-face teaching modality. While comprehension was an issue in the traditional face-to-face teaching modality, this is somehow compounded when the online teaching modality is used as the primary learning channel. Furthermore, challenges in case studies and problem-solving are exacerbated with this teaching modality. From the faculty members' perspective, achieving a high-quality online course entails the alignment of course objectives, instructional materials, and assessment utilizing technology while sustaining students' engagement in the course (Myring et al., 2014).

Juan, for instance, narrated the following:

"In an online class, it is very tiring. Like there are times that I ask myself if I will still continue because I cannot bear the online class. So I am really thinking if I will still continue because in the end I will still struggle. On the other hand, if I will stop, I will be left behind".

\begin{abstract}
"In my point of view, teachers make me study in my own capacity, gave us quiz; then, they will score and give grades based on my capacity, then they do not give inputs, and the score depends solely on me, and they do not give me learnings. We meet only in groups, and they will give instructions, then after that, give us the chapter quiz next meeting".
\end{abstract}

Online learning causes fundamental to complicated issues; students dislike much of the product itself; they need enough sleep. They do not enjoy learning on their own; they do not prefer staying in front of the screen for a long time; they find being online "distracting;" and they equate online learning to low quality, a "dumbed down version of face to face learning," "an imitation of school," and "lonely." It is not merely that students want to see their friends, but they especially want to be part of a group of learners (Burns, 2020). The narration of Maria affirmed this:

\footnotetext{
"Online class is draining."

"In the house, after you watch the screen the whole day, you have to study on the screen again so that it is very tiring to focus on the screen the whole day."
}

\section{Coping with technical issues}

During the pre-pandemic era, the financial and banking industries have already made strides in electronic banking. On the other hand, some elite educational institutions migrated to electronic books for their students, downloadable through prescribed tablet computers. The rest of the sectors in the society viewed these as channels that were not necessary, and therefore, can be lived without. However, the pandemic made everyone realize that these channels are necessary - in almost all spheres of activities.

While it is true that virtual classes on personal tablets may be a norm in other parts of Asia, many students in the Philippines, particularly in Bacolod City, rely on lessons and assignments sent via a free learning management system or email. The poorer and less technically savvy individual families are, the further their students are left behind. These students cannot afford these digital devices and data plans. 
As stated by Elena:

"Online class is difficult because sometimes my classmates have no connection. If sometimes the teachers will give a test or require to submit assignments, eight or nine in the evening, they have to look for a signal, and it is very difficult for them, unlike me that I'm just inside my house".

Jose also narrated that:

"Some students were not able to secure cameras before COVID 19, so their attendance was affected because when taking pictures for attendance, they cannot be seen".

Maria concluded that:

"The enemy is the connectivity."

The technology divide could reach a high degree if access to education is prescribed by having the latest technology and connectivity. Students try their best to use what they have at home and ensure they don't get left behind. Although online learning may be the best option we have, for now, one could still not help but wonder how everyone is adjusting and coping with the problems that arise while attending online classes, especially during synchronous classes. Synchronous classes are classes conducted in real-time, and during this time, a lot of problems arise. Sadly most of these problems are technical. The Philippines is an internet-challenged country, a problem that has caused delays in implementing remote learning. Though there are internet plans, some cannot afford them; hence, there was never a day when a student has not voiced out complaints (Amadora, 2020).

\section{Compromising values}

The journey is the destination - an adage that maybe aptly visited while the students and teachers are adjusting to a continuous online teaching/learning modality. The students at the receiving end of this modality will have to integrate critical values into their learning journey. A value is the worth a person gives to a thing, action, state, or notion. For a value to be of intrinsic worth, it has to be a principle. When people experience intense stress and pressure, their ability for decision-making and acting in good faith often suffer. Online students in today's delivery of instruction are under intense tension to perform and achieve learning in their courses, balancing busy schedules and family lives with obtaining a decent degree to boost their job possibilities. Combine these stressors with the unknown produced through online interactions, as well as the commonality of cheating, and the importance of securing academic integrity in online programs is certain (Morgan, 2018). As described by Elena:

"It is unfair in phase 1 because we had a quiz, and my classmates were chatting

in the group chat that they were searching in google the answers. It is unfair for those who studied."

The principles of integrity, determination, and patience are of prime importance in this teaching/ learning modality. In the traditional classroom setting, some students struggle to practice integrity during examinations is a reality. This is a challenge for teachers to safeguard the integrity of their examination and influence some students to practice and keep the value of integrity.

As narrated by Maria also:

"I studied for many hours, and then during the exam, some of my classmates took the easy way because they cheated."

Without educators' physical presence to monitor students as they answer seat works, tests, and exams online, academic integrity and other values necessary for holistic student formation come under question and warrant valid concerns from administrators, faculty, and parents alike. For example, academic dishonesty incidents are perceived to be more challenging to identify and resolve online than those within a physical classroom setting. It is a reasonable presumption that values constitute an integral part of any learner's lived experiences in online learning, not just accountancy students. 


\section{Adjusting to the new learning environment}

In the traditional paradigm, the bulk of learning was transmitted and imbibed in a physical classroom setting. On the other hand, the home setting was traditionally for family bonding, rest, and recreation. When used as a venue for learning, the home setting was to review the subjects taught in the traditional physical classroom. The challenge for virtual learning is the blurring of the boundaries between the home and classroom settings.

Juan described:

"While at online class, my mother shouted at me to wash the dishes."

Jose also has something to say:

"That you should do your work because if you have an online class, the setting is at

home, so the mood is chilling, and there is a tendency to procrastinate or be lazy."

The mere act of pursuing education, regardless of the traditional or online distance in delivery, obliged the participants to sort out their priorities. The layer of a deemed online space represented adjustments to be made based on identity and solidarity in an online environment. The distance layer entailed various kinds, particularly "transactional distance or psychological and communication space" between parties (Moore, 1993, cited in Wozniak \& McEldowney, 2015).

As with all people thrust into positions that place them in environments different from the ones they are accustomed to, learners engaged in online learning adjust their behavior due to adapting to the switch from education occurring within the confines of a physical classroom setting. These behavioral adjustments warrant closer inspection for educators and administration to see better the implications such modifications may have for the continued usage of online learning as the accepted mode of delivery.

In this study, supplemental analyses highlighted students' more positive reactions and learning adaptability and reported greater belonging and mattering feelings. The current findings support the role of adaptability and the notable challenges encountered by college students who underwent adjustment in their learning and life conditions due to rapidly adjusting to the changes and uncertainty caused by the COVID-19 pandemic (Besser et al., 2020).

In this pandemic, where online learning in a home setting is a must, behavioral adjustments will have to be undertaken by both teachers and students in order for the learning process to be as effective as the traditional classroom setting. Students' involvement in the process of creating their learning environment can motivate them to achieve their goals.

\section{Longing for a physical classroom teaching}

According to Philipps (2014), the physical structure of a classroom is a critical variable in affecting student morale and learning. No wonder the four participants unanimously shared their desire to go back to the physical classroom to learn and study. There are three possible causes of this desire: resistance to change, social interaction with peers, and readily available coaching from teachers.

As also cited by Jose:

"What I can comment is that I miss the face-to-face classroom teaching because the learnings are different from online classes."

Virtual learning cannot simply replace someone's happiness in interacting with friends and teachers in the flesh. As the saying goes, absence makes the heart grow fonder. Many students feel lonely due to isolation brought by quarantine restrictions. They look forward to the day they reunite with their peers. Students miss physical activities and interactions associated with face-toface classes (Nepomuceno, 2020).

As further said by Jose:

"Because in face to face there is, for example, a feeling of excitement and if you go to school and if you take the quiz, it is different when you are in your homes. In face to face, you are challenged to study".

Any change poses adverse reactions. The status quo is always the comfort zone. When the change involves using resources, technology, efficiency in knowledge absorption, and re-alignment in values, the resistance will even be greater despite the benefits of this change. 
A more practical reason for this desire to go back to the classroom setting is the presence of teachers and fellow students who can readily coach other students should there be points for clarification in the topics being discussed. This is coaching avenue is not readily available in a virtual classroom setting. Though teachers and fellow students may still be willing to coach other students, the limitations on resources and technology may constrain this option.

As cited in Maria's narration:

"In face-to-face, I am diligent, and the atmosphere is different if you are inside the classroom where you can see your teacher, your classmates, then you are motivated and realized that you are really in school."

"It is different in face to face, you are equal in footing and in discipline."

As network-based systems continue to assimilate themselves in contemporary education, it is still widely held and practiced that the traditional classroom setup remains the choice of setting by schools and institutions worldwide, the default standard for learning delivery (Saunders et al., 2008).

As validated by Elena:

"Interaction is good in face to face. You can see the responses of the students, unlike in online class they are talking to their laptop and they cannot get the responses".

\section{Persevering online classes}

Thanks to modern technology and the internet, learning continues for students amid the COVID-19 crisis. Even with the new learning setup, students are lucky as they can proceed with their studies though they are focused on submitting the requirements than understanding the lessons (Nepomuceno, 2020).

In any learning endeavor, both students and teachers acknowledge a 'learning curve,' where adjustments in the teaching method and study habits will have to be incorporated so the knowledge can be effectively imparted and imbibed.

Jose said that:

"If ever the same setting will continue, I hope both the teachers and the students will develop more consideration to one another."

In an online classroom setting, this learning curve has gotten steeper, as evidenced by the students' lived experiences. The students' access to the teachers' guidance is severely constrained by the former's available resources, software, and hardware.

While effort is important when attempting work of any kind, perseverance in school is frequently depicted as a quality either a student has or doesn't have, as if the circumstances surrounding the student's struggles were irrelevant. And far too often, teachers and others use concepts like perseverance to blame students from disadvantaged backgrounds for "lacking motivation" when the learning environment itself is largely to blame (Toshalis, 2018). Students persevere in a learning experience when they feel included. They have reasons to value the outcomes, relationships with their teachers are not strained, and they believe that they will be successful despite the circumstance.

Elena has sentiments:

"I am happy because I can continue my studies even though there is a pandemic."

Indicators of positive mood include levels of enjoyment, satisfaction, and optimism, given the role of confidence, hope, and optimism in flexibility and positive educational outcomes (Besser et al., 2020).

The significant struggles that the data reflect warrant the natural reaction upon students to find ways to adapt to the challenges posed by the pandemic. Because of the participants' experiences and struggles with online learning, they cultivated resilience which enabled them to bravely face their challenges, entailing perseverance to continue their education.

The result has a noteworthy implication. The role of adaptability and overcoming these challenges positively affected the participants as resilient learners during the COVID-19 pandemic. 


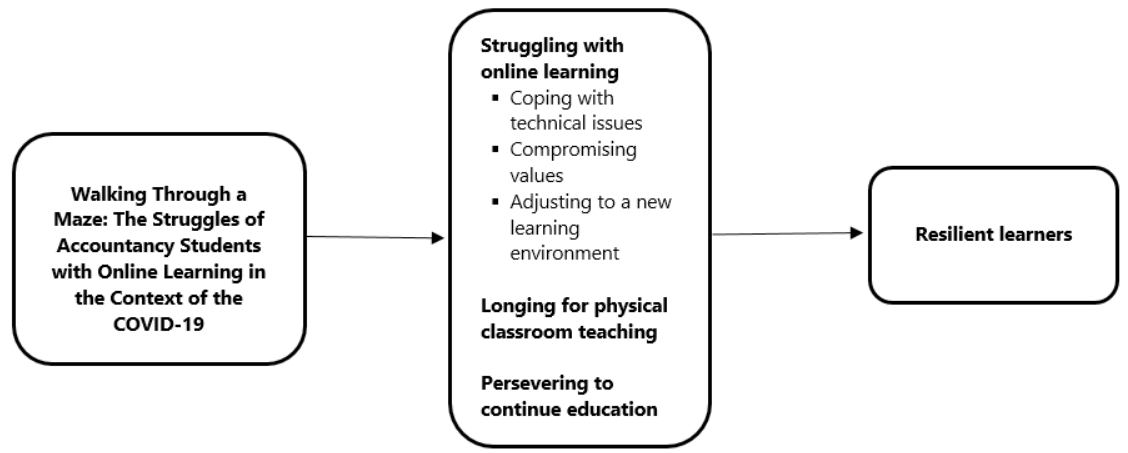

Figure 1. Conceptual Model of the Online Class Experience of Accountancy Students

\subsection{Conclusion}

The different experiences lived by the participants constitute transitions from struggles to perseverance as eventually they become resilient learners from a traditional classroom learning to an online learning modality brought about by the pandemic. While the experience with the online classes may have slightly differed among the participants, there were commonalities in their lived experiences. Common observations of the lived experiences of accountancy students are the pervasive notion that the online learning modality is ineffective, an added emotional/psychological stress from perceived inconsiderate teachers, and an undue physical strain in the learning process.

The online learning session relies heavily on technology. Not all students can afford the latest software and hardware and a reliable internet connection for an uninterrupted and stable internet connection. With the unstable internet connection for some participants, there will be moments of lags and buffering in their mobile phone or computer systems resulting in truncated and sometimes missing data transmission. This resulted in incomplete information during lectures and outright involuntary logging out during examinations. Hence, the perceived struggles and coping of these participants in this aspect. The participants missed the important calculation process, examples, and board works that cannot be readily implemented using an online learning facility. Moreover, the online lectures are sometimes pre-recorded, and the students cannot raise their questions in realtime. They will have to wait for the next lecture when the educator is physically present during the online classroom to raise their questions and clarifications.

In the end, though the participants struggled in most of their experiences, the participants also acknowledged that even though amid the pandemic, they are still able to continue their education and they persevere to overcome the challenges brought about by this online learning, thus they become resilient learners.

\section{REFERENCES}

Amadora, M. (2020 September 18). Common problems that occur during online classes. Manila Bulletin. https:// mb.com.ph/2020/09/18/common-problems-that-occur-during-online-classes/

Besser, A., Flett, G. L., \& Zeigler-Hill, V. (2020). Adaptability to a sudden transition to online learning during the COVID-19 pandemic: Understanding the challenges for students. Scholarship of Teaching and Learning in Psychology. https://doi.org/10.1037/stl0000198

Burns, M. (2020 June 10). Online education's COVID-19 struggles. UKFIET: The Education and Development Forum. https://www.ukfiet.org/2020/online-educations-covid-19-struggles/

Chen, B. (2020). Designing for online distance education. https://www.researchgate.net/

Creswell, J. (2014). Research design. $4^{\text {th }}$ Edition. SAGE Publications Inc.

Eddin, S. J. (2020 May 5). COVID-19 and changing to online learning. https://blogs.lt.vt.edu/ sarajamaleddin/2020/05/05/covid-19-and-changing-to-online-learning/ 
Hallare, K. (2020 July 2). DepEd, CHED asked to 'initiate academic freeze' until virus mass testing is conducted. Inquirer News. https://newsinfo.inquirer.net/1300803/depedched-asked-to-initiate-academic-freeze-untilvirus-mass-testing-is-conducted

Lichtman, M. (2012). Qualitative research in education a user's guide. $3^{\text {rd }}$ Edition.

Mansour, B., \& Mupinga, D. (2007). Students' Positive and Negative Experiences in Hybrid and Online Classes. College Student Journal. 41. 242-248.

Morgan, J. (2018 February 14). How students cheat online and why stopping them matters. Inside Higher Ed. https://www.insidehighered.com/digital-learning/views/2018/02/14/creative-cheating-online-learning-andimportance-academic

Myring, M., Bott, J. P., \& Edwards, R. (2014). New approaches to online accounting education. The CPA Journal, 84(8), 66-71. https://nasba.org/files/2013/08/Online-Accounting-Education-RR-Preliminary-Draft.pdf

Nepomuceno, P. (2020 October 2). Education amid COVID-19: A longing to reunite with teachers, pals. Philippine News Agency. https://www. Pna.gov.ph/articles/1117294

Philipps, M. (2014). A place for Learning: The physical environment of classrooms. https://www.edutopia.org/

San Juan, A. (2020 September 10). Youth group insists on an 'academic freeze' for this year. Manila Bulletin. https://mb.com.ph/2020/09/10/youth-group-insists-on-academic-freeze-for-this-year/

Saunders, G., Wenzel, L., \& Stivason, C. T. (2008). Internet courses: Who is doing the work? Journal of College Teaching \& Learning (TLC), 5(6). https://doi.org/10.19030/tlc.v5i6.1251

Snow, K., Wardley, L., Carter, L., \& Maher, P. (2019). Lived experiences of online and experiential learning in four undergraduate professional programs. Collected Essays on Learning and Teaching, 12, 79-93. https://doi. org/10.22329/celt.v12i0.5388

Toshalis, E. (2018 April 13). On perseverance in the classroom. Students at the Center Hub. https:// studentsatthecenterhub.org/resource/on-perseverance-in-the-classroom/

World Economic Forum 2020. COVID-19: The Great Reset | World Economic Forum (weforum.org)

Wozniak, H., \& McEldowney, R. (2015). Layers of transition: The lived experiences of online distance learners. Research and Development in Higher Education: Learning for Life and Work in a Complex World, 38, 505-515.

Yarrow, N. (2020, June 23). COVID-19 in East Asia: How the region's higher education systems are addressing the crisis to adapt to the future. World Bank Blogs. https://blogs.worldbank.org/education/covid-19-east-asiahow-regions-higher-education-systems-are-addressing-crisis-adapt

\section{Correspondence:}

GRACE L. LOPENA*

gllocsin@gmail.com

https://orcid.org/0000-0002-5744-9621

NENETTE D. PADILLA

dedelpadilla@gmail.com

https://orcid.org/0000-0002-3655-190X

DENNIS V. MADRIGAL

dennis_madrigal@yahoo.com

https://orcid.org/0000-0001-5548-2682

*Principal Correspondent 